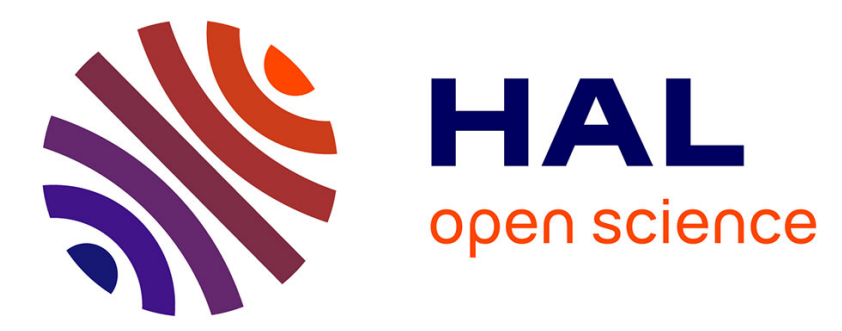

\title{
Coupled Chemical and Mechanical Damage in Calcium Leached Cementitious Structures
}

Caroline Le Bellégo, Gilles Pijaudier-Cabot, Bruno Gérard, Jean-François

Dubé, Laurent Molez

\section{- To cite this version:}

Caroline Le Bellégo, Gilles Pijaudier-Cabot, Bruno Gérard, Jean-François Dubé, Laurent Molez. Coupled Chemical and Mechanical Damage in Calcium Leached Cementitious Structures. Journal of Engineering Mechanics - ASCE, 2003, 129 (3), pp.333-341. 10.1061/(ASCE)0733-9399(2003)129:3(333) . hal-01006002

\section{HAL Id: hal-01006002 \\ https://hal.science/hal-01006002}

Submitted on 29 Jan 2017

HAL is a multi-disciplinary open access archive for the deposit and dissemination of scientific research documents, whether they are published or not. The documents may come from teaching and research institutions in France or abroad, or from public or private research centers.
L'archive ouverte pluridisciplinaire HAL, est destinée au dépôt et à la diffusion de documents scientifiques de niveau recherche, publiés ou non, émanant des établissements d'enseignement et de recherche français ou étrangers, des laboratoires publics ou privés. 


\title{
Coupled Mechanical and Chemical Damage in Calcium Leached Cementitious Structures
}

\author{
Caroline Le Bellégo ${ }^{1}$; Gilles Pijaudier-Cabot ${ }^{2}$; Bruno Gérard ${ }^{3}$; Jean-François Dubé ${ }^{4}$; and Laurent Molez ${ }^{5}$
}

\begin{abstract}
Long-term durability of concrete structures must be faced both from the point of view of cracking and physical degradations. In this paper, the relevance and the sensitivity of an existing constitutive relation aimed at modeling mechanical and chemical damage is examined. This constitutive relation is based on a scalar continuum damage model. The chemical degradation mechanism is calcium leaching. It is observed that the model predictions, i.e., the lifetime of cement-based beams subjected to leaching, are very sensitive on the tensile strength and fracture energy of the sound material. The existing model predicts the response of bending beams subjected to various states of leaching prior to any mechanical loading. The simulation of the size effect tests shows that the mechanical internal length and the damage threshold of the material cannot be considered to be constant. The internal length ought to decrease and the damage threshold should increase.
\end{abstract}

keywords: Concrete structures; Cracking; Degradation; Damage; Simulation.

\section{Introduction}

The long-term behavior of concrete structures subjected to environmental damage is a topic of the utmost importance for waste containment disposals, for instance. In the case of long-life wastes (such as radioactive wastes), the models cannot rely on experimental data over the entire service life of the disposal, which spans over several hundred years. Assessing such structures and comparing several possible designs prior to their construction have to rely on robust and accurate computational tools, in which the knowledge of the various degradation mechanisms at the material level must be incorporated. In this paper, the mechanism of degradation considered is leaching due to water, and particularly calcium leaching as calcium is the most important element in the hydrated cement paste. The consequences of calcium leaching are an increase of porosity, a decrease of the elastic stiffness, and a decrease of strength (Carde 1996; Gérard 1996; Carde and Fran-

${ }^{1}$ Electricité de France, EDF-CIPN, 140 Ave Viton, F-13401 Marseille cedex, France and LMT-Cachan, ENS de Cachan, 61 avenue du Pdt Wilson 94235 Cachan cedex, France.

${ }^{2}$ R\&DO, Laboratoire de Génie Civil de Nantes Saint-Nazaire, Ecole Centrale de Nantes, B.P. 92101, F-44321 Nantes cedex 3, France (corresponding author). Also at Institut Univ. de France. E-mail: Gilles.Pijaudier-Cabot@ec-nantes.fr

${ }^{3}$ LMT-Cachan, ENS de Cachan, 61 avenue du Pdt Wilson 94235 Cachan cedex, France and OXAND, 1 rue de la Crête, F-77690 Montigny sur Loing, France; formerly, EDF-R\&D, France.

${ }^{4}$ R\&Do, Laboratorie de Génie Civil de Nantes Saint-Nazaire, Ecole Centrale de Nantes, BP 92101, F-44321 Nantes cedex 3, France.

${ }^{5}$ LMT-Cachan, ENS de Cachan, 61 avenue du Pdt Wilson 94235 Cachan cedex, France. cois 1997). It is this decrease of the mechanical properties that is addressed more specifically in this paper. The main reason is that for lifetime assessments, chemical degradation mechanisms must be superimposed to mechanical loads so that cracking may be predicted.

As leaching is a very slow process, accelerated experimental procedures are needed in order to calibrate models, and to validate them subsequently. Goncalves and Rodrigues (1991) and Schneider and Chen $(1998,1999)$ among others, have studied the influence of calcium leaching on the residual strength of beams for different cements subjected to different aggressive solutions. Carde (1996) used ammonium nitrate as an aggressive solution for accelerated leaching. Le Bellégo et al. (2000) have carried out size effect tests on leached specimens for different degradation rates, and more recently, Ulm and coworkers (2001) used a similar method in order to accelerate leaching.

Various models have been developed to describe calcium leaching, its effect on the mechanical properties of the leached material, and mechanical damage as well. Ulm and coworkers $(1999,2001)$ used a chemoplastic approach based on the mechanics of porous materials. Kuhl et al. (2000) devised a continuum damage model on the same basis. Gérard (1996) proposed a nonlocal damage model coupled with leaching effects. It is based on the definition of two damage variables: One is due to mechanical loads and the other one, which could be called a chemical ageing variable, accounts for chemical damage. These models could provide predictions of the residual strength and of the lifetime of concrete structures subjected to aggressive water but their range of validity in structural computations needs to be explored still. Such an assessment is the prime objective of this contribution, in which the experiments obtained by Le Bellégo et al. (2000) will serve as reference data. The constitutive relations due to Gérard will be considered as an illustration. Among the models mentioned above, it is the only one that contains an internal length. This is a crucial parameter that is needed in order to ensure a consistent mechanical description of failure due to strain and damage localization, without ill posedness of boundary-value problems (see, e.g., Pijaudier-Cabot and Bazant 1987; De Borst 
et al. 1993). Therefore, it is capable of a proper modeling of failure (Gérard et al. 1998).

In the next section, we present briefly the constitutive relations used in this paper. The computer implementation of this model is recalled and the sensitivity of the model parameters on the residual strength and lifetime of leached beams is investigated. Finally, the model response is compared to size effect experiments. Examined with the help of the size effect law, which contains a definition of brittleness as the transition of a strength of material criterion to a linear elastic fracture mechanics one (Bazant and Planas 1998), the model fails to describe the increase of brittleness of the specimens during leaching. Such an increase may be represented by a decrease of the internal length and by an increase of the damage threshold essentially. New model parameters for the leached material are obtained.

\section{Constitutive Relation}

We are going to describe chemical damage very briefly only, and to see how it can be coupled with a scalar mechanical damage model. Full details on the chemical damage model can be found in Gérard (1996).

\section{Chemical Damage}

Concrete is a reactive porous material. Hydrates and water are the main components. Solid phases are in thermodynamic equilibrium with the surrounding pore solution chemistry and calcium is the main chemical component of the binder. The hydrates leaching process is caused by the difference of composition and chemical activity between water in contact with concrete and the pore solution inside concrete. The difference between the pore solution and the external solution causes the motion of ions out of the cement paste. This overall motion of ions breaks the thermodynamic equilibrium established between the pore solution and the hydration products, and favors the dissolution of solid phases. The present simplified approach avoids considering all the elementary chemical mechanisms and focuses on the evolution of one variable only, the amount of calcium ions in the liquid phase of the hardened cement paste (Gérard et al. 1999). It is obtained by solving a nonlinear diffusion equation

$$
\frac{\partial C_{\text {solid }}}{\partial C} \frac{\partial C}{\partial t}=\operatorname{div}[D(C) \operatorname{gra} d(C)]
$$

where $C_{\text {solid }}=$ amount of calcium in the solid phase; and $C=$ amount of calcium ions in the liquid phase. A mathematical relationship for the calcium solid-liquid equilibrium can be found in Gérard (1996). It is a function of the cement chemistry and of the water-to-cement ratio. The diffusion coefficient $D$ is not constant. It is related to the volume fraction of the different solid phases initially. During the leaching process, it varies between that of the virgin material and the diffusion coefficient of calcium ions in water (when the material is totally cracked).

\section{Mechanical Damage}

Microcracking due to mechanical loads is captured with a scalar damage model due to Mazars (1984), described completely, e.g., in Mazars and Pijaudier-Cabot (1996). It is briefly recalled in the following. The stress-strain relation is

$$
\sigma_{i j}=(1-d) \Lambda_{i j k l} \varepsilon_{k l}
$$

where $\sigma_{i j}$ and $\varepsilon_{i j}=$ components of the stress and strain tensors, respectively, $(i, j, k, l \in[1,3]) ; \Lambda_{i j k l}=$ initial stiffness moduli; and $d=$ damage variable. $E$ and $\nu=$ initial Young's modulus and Poisson's ratio, respectively. For the purpose of defining damage growth, the equivalent strain is introduced first

$$
\widetilde{\varepsilon}=\sqrt{\sum_{i=1}^{3}\left(\left\langle\varepsilon_{i}\right\rangle_{+}\right)^{2}}
$$

where $\langle.\rangle_{+}=$Macauley bracket and $\varepsilon_{i}=$ principal strains. In order to avoid ill-posedness due to strain softening, the mechanical model is enriched with an internal length (Pijaudier-Cabot and Bazant 1987). The nonlocal variable $\bar{\varepsilon}$ is defined

$$
\bar{\varepsilon}(x)=\frac{1}{V_{r}(x)} \int_{\Omega} \psi(x-s) \widetilde{\varepsilon}(s) d s \text { with } V_{r}(x)=\int_{\Omega} \psi(x-s) d s
$$

where $\Omega=$ volume of the structure; $V_{r}(x)=$ representative volume at point $x$; and $\psi(x-s)=$ weight function

$$
\psi(x-s)=\exp \left(-\frac{4\|x-s\|^{2}}{l_{c}^{2}}\right)
$$

where $l_{c}=$ internal length of the nonlocal continuum. $\bar{\varepsilon}$ = variable that controls the growth of damage according to the following conditions:

$$
F(\bar{\varepsilon})=\bar{\varepsilon}-\kappa
$$

$$
\begin{aligned}
& \text { if } F(\bar{\varepsilon})=0 \text { and } \dot{\bar{\varepsilon}}>0 \\
& \text { then }\left\{\begin{array}{c}
\dot{d}=h(\kappa) \\
\dot{\kappa}=\dot{\bar{\varepsilon}}
\end{array} \text { with the condition } \dot{d} \geqslant 0\right. \\
& \text { else }\left\{\begin{array}{l}
\dot{d}=0 \\
\dot{\kappa}=0
\end{array}\right.
\end{aligned}
$$

$\kappa=$ softening parameter and takes the largest value of $\bar{\varepsilon}$ ever reached during the previous loading history at a given time and at the considered point in the medium. Initially, $\kappa=\kappa_{0}$, where $\kappa_{0}$ is the threshold of damage. The damage evolution law $h(\kappa)$ in Eq. $(6 b)$, is defined in an integrated form. In particular, the tensile damage growth is

$$
d_{t}=1-\frac{\kappa_{0}\left(1-A_{t}\right)}{\kappa}-\frac{A_{t}}{\exp \left[B_{t}\left(\kappa-\kappa_{0}\right)\right]}
$$

where constants $A_{t}, B_{t}=$ model parameters which must be obtained from a fit of experimental data (e.g., bending beams).

\section{Chemomechanical Coupling}

The influence of chemical damage on the mechanical properties of the material may be introduced in the stress-strain relations following at least two methods. In the first one, which is inspired from the works of Ulm and Coussy (1996), the chemical degradation enters in the plastic yield function and, at the same time, changes the elastic stiffness of the solid skeleton of the material. Accordingly and within the context of continuum damage mechanics, the evolution of damage can be rewritten in a generic form as

$$
\dot{d}=F(\bar{\varepsilon})+G(C)
$$

For the sake of simplicity, a single phase material is considered only. The contribution to the growth of damage of each separate mechanism appears explicitly: Damage growth due to mechanical 


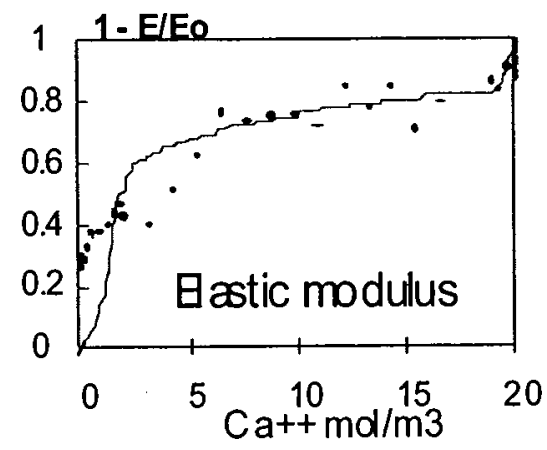

Fig. 1. Chemical damage function

loads is $F(\bar{\varepsilon})$ [e.g., as defined by Eqs. $(6 a)$ and $(6 b)$ ] and damage growth due to leaching is defined by the function $G(C)$. One has to check, however, that the damage variable ranges between 0 and 1, which means that the functions $F(\bar{\varepsilon})$ and $G(C)$ cannot be independent.

A second method consists of adding a new chemical damage variable $V$ on top of the mechanical one. This chemically induced damage variable is an independent contribution to the weakening of the material. It is a new internal variable. This method has been chosen by Gérard (1996), Saetta et al. (1999), Kuhl et al. (2000), Meftah et al. (2000), and Stabler and Baker (2000) for environmental (chemical and thermal) damage modeling. The corresponding stress-strain relation reads

$$
\sigma_{i j}=(1-d)(1-V) \Lambda_{i j k l} \varepsilon_{k l}
$$

$V=$ chemical damage, a function of the concentration $C$ of calcium ions in the pore solution: $V=g(C) . g=$ experimentally determined function shown in Fig. 1. It may be also related to the porosity of the material in the case of a cement paste (Ulm et al. 1999). $d=$ the mechanical damage variable, same as in the previous section. Here, the two evolutions of damage, chemical, and mechanical, are completely independent.

In order to appreciate the differences between those two formulations, it is interesting to compare intrinsic mechanical dissipations. This dissipation is defined as the absolute value of the amount of mechanical internal energy that cannot be recovered upon unloading, when damage is constant

$$
\dot{\phi}=\left|\frac{d}{d t}\left(\frac{1}{2} \sigma_{i j} \varepsilon_{i j}\right)-\left(\sigma_{i j} \dot{\varepsilon}_{i j}\right)_{\text {constant damage }}\right|
$$

In the first approach, the energy dissipated due to damage is

$$
\dot{\phi}=\frac{1}{2} \varepsilon_{i j} \Lambda_{i j k l} \varepsilon_{k l} \dot{d}=\frac{1}{2} \varepsilon_{i j} \Lambda_{i j k l} \varepsilon_{k l} F(\bar{\varepsilon})+\frac{1}{2} \varepsilon_{i j} \Lambda_{i j k l} \varepsilon_{k l} G(C)
$$

The thermodynamic force associated to damage is the same for the two components, the mechanical and the chemical ones. It is the prefactor to the damage growth functions $F(\bar{\varepsilon})$ and $G(C)$. The entire material dissipation, which is the integration of the dissipation for damage values ranging between zero and one is split into two terms: One is mechanical, and a second one is chemical. For instance, if the material has already suffered chemical damage without any applied mechanical load, the strain energy that can be converted into dissipation due to mechanical loads alone (during a proportional loading) is the strain energy of the sound material decreased by the amount already consumed in the chemical process [Fig. 2(a)]. The energy dissipation rate in the second formulation is different

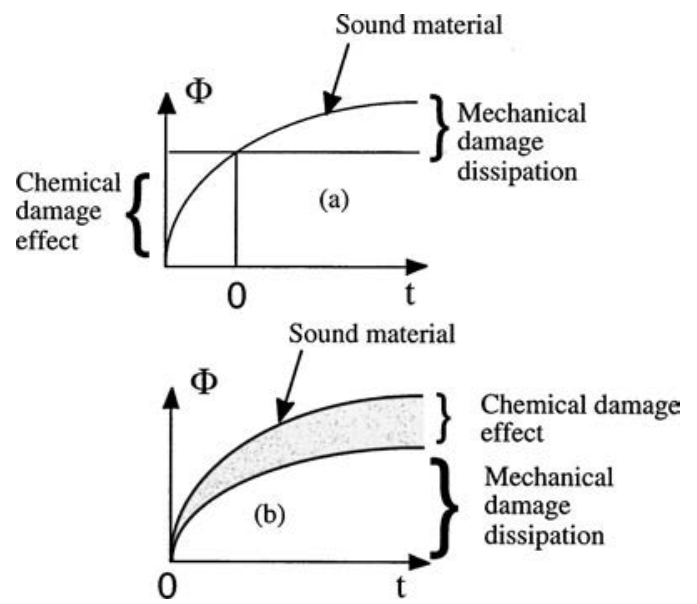

Fig. 2. Dissipation due to mechanical damage after chemical damage in the case of additive chemomechanical coupling (a) and multiplicative chemomechanical coupling (b)

$$
\dot{\phi}=\frac{(1-V)}{2} \varepsilon_{i j} \Lambda_{i j k l} \varepsilon_{k l} \dot{d}+\frac{(1-d)}{2} \varepsilon_{i j} \Lambda_{i j k l} \varepsilon_{k l} \dot{V}
$$

At constant values of $V(\dot{V}=0)$, the mechanical damage energy dissipation is decreased by the multiplicative term $(1-V)$. If the material is in an initial (homogeneous) state of chemically induced damage, the mechanical damage dissipation measured during a proportional loading should be proportional to that of the sound material [see Fig. 2(b)]. Hence, for a monotonically increasing load, the fracture energy density of a leached material, which is the integral of Eq. (10) up to complete failure (or the area under the stress-strain curve), should be $(1-V)$ times that of the sound material. Assuming that the internal length does not change upon leaching, the same holds for the fracture energy $G_{f}$ computed with the approximate formula due to Mazars and Pijaudier-Cabot (1996).

It seems, for now, difficult to discriminate these two chemomechanical models on the basis of the above differences. A major reason is that these are point-wise considerations. During fracture, the shape of the process zone (FPZ) controls the total amount of mechanically dissipated energy. The energy dissipation densities in Eqs. (11) and (12) have to be integrated over the FPZ and without an accurate description of how the FPZ evolves during chemomechanical loads, it is hard to draw any conclusion. In the remaining part of this paper, we will focus attention on the second formulation and examine its predictive capabilities.

\section{Sensitivity Analysis}

The chemomechanical damage model has been implemented in a finite-element code according to a staggered scheme. The diffusion problem [Eq. (1)] is solved first over a time step, considering that mechanical damage is constant, then the mechanical problem is solved assuming that the chemical damage is constant. The time integration scheme in the diffusion problem is unconditionally stable and the mechanical solver uses a secant stiffness algorithm that provides robust results with such a damage model (Rodriguez-Ferran and Huerta 2000). More details on the finiteelement implementation can be also found in Molez et al. (1998). It should be stated here that both the diffusion problem and the mechanical problem are nonlinear. They are coupled, although the 


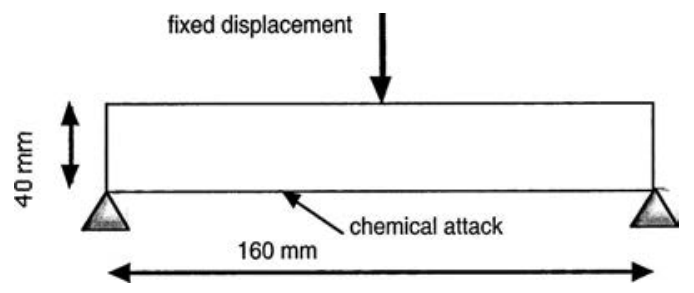

Fig. 3. Three-point bend beam subjected to chemical attack and constant deflection

influence of mechanical damage on the diffusion problem is quite small. For good accuracy, the finite-element grid and the time steps needed to solve the diffusion problem are rather small (smaller than what is needed for the damage problem). These are two reasons (besides simplicity of implementation) why a staggered scheme has been preferred to a fully coupled computational approach as it provides a sufficient accuracy. Note also that it is possible to control the accuracy of the time integration in the diffusion process (Diez et al. 2002).

Let us perform first a sensitivity analysis and consider in this section a three-point bending beam subjected to an external constant deflection and a chemical attack by pure water on the tensile bottom face (Fig. 3). This is a plane stress calculation. Vertical displacements are prevented at the bottom supports, and fixed at midspan on the upper part of the beam under the load. Horizontal displacement is prevented at the left-side support. The central half of the beam is treated with the damage model while the rest is assumed to remain elastic. The diffusion coefficient is assumed to remain constant (Table 1). All the computations have been performed with the same mesh of four nodded square elements of size $2.5 \mathrm{~mm}$. Initially, the tensile stress at the bottom is $80 \%$ of the tensile strength. Due to leaching, chemical damage propagates from the bottom to the upper faces of the beam. The strain increases and mechanical damage is triggered in the central part of the beam. As a consequence, the beam carries less load and failure occurs eventually. The time to failure is the lifetime of the beam.

For a Mode I crack propagating in an infinite body, it is possible to show that the fracture energy is roughly proportional to the area under the stress-strain curve and to the internal length (Mazars and Pijaudier-Cabot 1996). The tensile strength of concrete has been varied first. In order to keep constant the fracture energy, and therefore the area under the stress-strain curve for a constant internal length, $B_{t}$ and $\kappa_{0}$ [Eq. (7)] were changed according to Table 2. Fig. 4 shows the evolution of the carrying load with time. When the tensile strength is increased, the threshold of damage increases too. Therefore, the chemical degradation needed in order to reach the threshold of mechanical damage must increase and the time to failure is also increased. Note that an increase of $30 \%$ of the strength provides an increase of $100 \%$ of the time to failure.

Because the internal length is proportional to the fracture energy, it is sufficient to change this parameter in order to change the fracture energy without changing the tensile strength. We can observe in Fig. 5 that the time to failure is extremely sensitive to

Table 1. Model Parameters for Evolution of Damage

\begin{tabular}{lcccccc}
\hline$E$ & $A_{t}$ & $B_{t}$ & $\kappa_{0}$ & $l_{c}$ & $v$ & $\mathrm{D}$ \\
\hline $35,000 \mathrm{MPa}$ & 1 & 6,000 & $1.510-4$ & $1 \mathrm{~cm}$ & 0.2 & $7 \times 10^{-10} \mathrm{~m}^{2} / \mathrm{s}$ \\
\hline
\end{tabular}

Table 2. Model Parameters for Analysis of Influence of Tensile Strength

\begin{tabular}{|c|c|c|c|}
\hline $\begin{array}{l}\text { Fracture energy and } \\
\text { constant parameters }\end{array}$ & $2.53 \times 10^{-2} \mathrm{~N} / \mathrm{m}$ & $A_{t}=1$ & $l_{c}=1 \mathrm{~cm}$ \\
\hline$B_{t}$ & $\kappa_{0}$ & $f_{t}(M P a)$ & \\
\hline 3,500 & $3.25 \times 10^{-5}$ & 3.53 & \\
\hline 6,000 & $1.5 \times 10^{-4}$ & 4.52 & \\
\hline 19,000 & $2.39 \times 10^{-4}$ & 7.10 & \\
\hline
\end{tabular}

the fracture energy. A $100 \%$ increase of the fracture energy $G_{f}$ results in a $600 \%$ increase of the time to failure.

These results demonstrate that the lifetime of the beam is extremely sensitive to the material strength and to the fracture energy. Both computations show also that for (statically determinate) bending beams and Mode I failure, an underestimation of the fracture energy and of the strength may yield a large underestimation of the lifetime. Small errors in the calibration may yield a great lack of accuracy of numerical predictions, on bending beams at least. These results underline also the need to calibrate accurately the model from experiments especially designed for obtaining the internal length of the material, such as size effect tests discussed in the next section.

\section{Residual Strength of Leached Beams}

We are now going to compare the model predictions to experimental results. The experimental data have been taken from Le Bellégo et al. (2000) and Le Bellégo (2001).

\section{Size Effect Tests on Leached Specimens}

The experimental program performed consists of residual strength tests: The residual behavior of mortar beams was obtained after leaching in an aggressive solution (ammonium nitrate). The specimens are mortar beams of rectangular cross section. In order to study the size effect, geometrically similar specimens of various height $D=80,160$, and $320 \mathrm{~mm}$, of length $L=4 \mathrm{D}$, and of thickness $b=40 \mathrm{~mm}$ kept constant for all the specimens have been tested. The length-to-height ratio is $L / D=4$ and the span-toheight ratio is $1 / D=3$. The beams were immersed into the aggressive solution during different periods of time $(28,56$, and 98 days). Only the two lateral sides were exposed in order to have a unidirectional leaching front. The leaching depth $X_{f}$ was measured at the end of each time period. It helped at defining the leaching rate $L_{R}=2 X_{f} / b$ which is the ratio of the leached cross section to the initial cross section of the beam. For 28, 56, and 98 days of leaching, the leaching rates are 45,62 , and $84 \%$, respectively. After the chemical degradation tests, the residual mechanical behavior of the beams was obtained from three-point bending tests. A notch of depth $D / 10$ and thickness $3 \mathrm{~mm}$ was sawed just before the mechanical test. The notch thickness was kept the same for all specimens. Its size is approximately that of the sand particles and the notch could be seen as a local initial defect in the beam. The response of bending beams entirely leached was also extrapolated from these data following the method described in Le Bellégo et al. (2000).

\section{Response of Leached Beams}

The parameters controlling chemical damage have been fitted independently, including the diffusion coefficient in Eq. (1) whose 


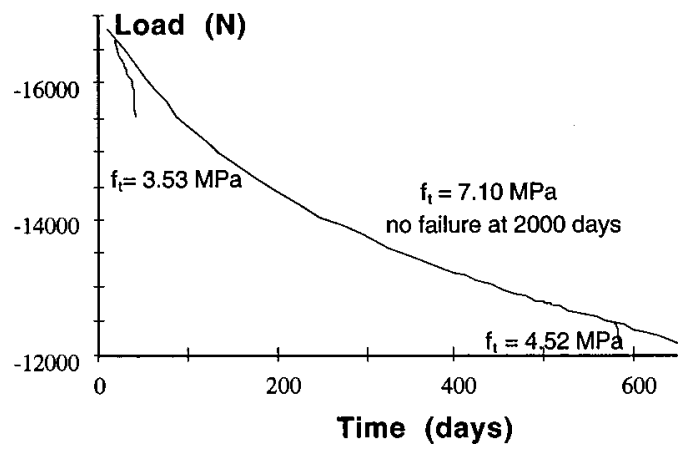

Fig. 4. Influence of tensile stress on lifetime predictions

variation depends on the type of accelerated leaching used in the experiments. Since the chemical model and its adaptation to accelerated leaching are rather complex, and considering the fact that they are not central in the present paper, they will not be detailed here. Note however that the diffusion coefficient in Eq. (1) depends on damage here (complete data are available in Le Bellégo 2001). The parameters entering in the mechanical model are provided in Table 3 . These parameters result from a manual (trial and error) fit of the size effect test data on sound beams. A full description of the calibration technique can be found in Le Bellégo et al. (2003).

It is now possible to compute the responses of beams at different leaching rates and to compare with the experiments. A onedimensional diffusion problem is solved first within the beam thickness in order to compute the calcium concentration. Then, the distribution of calcium ions is converted into a distribution of chemical damage according to the function plotted in Fig. 1. It is averaged over the thickness of the beam, the average chemical damage is inserted into the mechanical model (decrease of Young's modulus). Then, the load-deflection curves of the beams are computed. Within the fracture process zone the finite element should be smaller than the internal length. The finite-element meshes of geometrically similar beams should not be geometrically similar (unless the above requirement is met for each size). In the present computations, the finite elements placed in the fracture process zone (constant strain triangles) have a size of $1 / 3$ of the internal length approximately. Fig. 6 shows the numerical predictions for leaching rates of 45 and $64 \%$. Due to chemical damage, the average Young's moduli of the beams have been decreased by 25 and $40 \%$ in the mechanical computations, respectively. These comparisons can be considered to be quite satisfactory. The softening response for large beams is not very well described but the peak loads are predicted correctly. A better method might be to describe the exact variation of the chemical

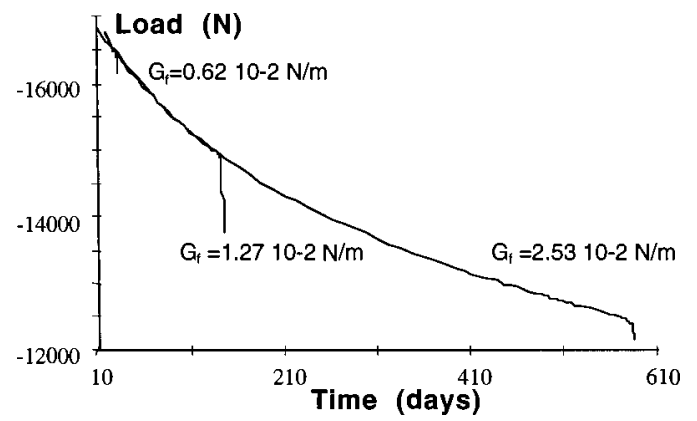

Fig. 5. Variation of lifetime predictions with fracture energy
Table 3. Set of Model Parameter in Size Effect Computations

\begin{tabular}{lccccc}
\hline$l_{c}$ & $\kappa_{0}$ & $A_{t}$ & $B_{t}$ & $E$ & $v$ \\
\hline $40 \mathrm{~mm}$ & $3 \times 10^{-5}$ & 0,95 & 9,000 & $38,500 \mathrm{MPa}$ & 0.24 \\
\hline
\end{tabular}

damage within the beam thickness in order to capture threedimensional effects. The interaction between the sound and leached parts of the beam could be captured more accurately too. It would require a full three-dimensional computation and a much greater computer effort, for a result that is not very different as observed by Le Bellégo (2001).

Finally, note also that the influence of the mechanical damage on the diffusion of calcium ions does not enter in the experiments because during the mechanical test leaching is stopped. Therefore, it is not necessary to carry out coupled chemical-mechanical computations, similar to those in the previous section. Since there is no calibration of model parameters involved in these calculations, they can be regarded as an evaluation of the capabilities of the present model. Recall, however, that the evaluation is incomplete because the coupling effect of damage on leaching is not considered.

\section{Prediction of Size Effect}

In order to examine the accuracy of the above computations, it is helpful to consider them on a size effect plot since it is an extrapolation of the model predictions for different sizes of specimens. A simple version of Bazant's size effect law is used (Bazant and Planas 1998). The nominal strength (MPa) is obtained with the formula
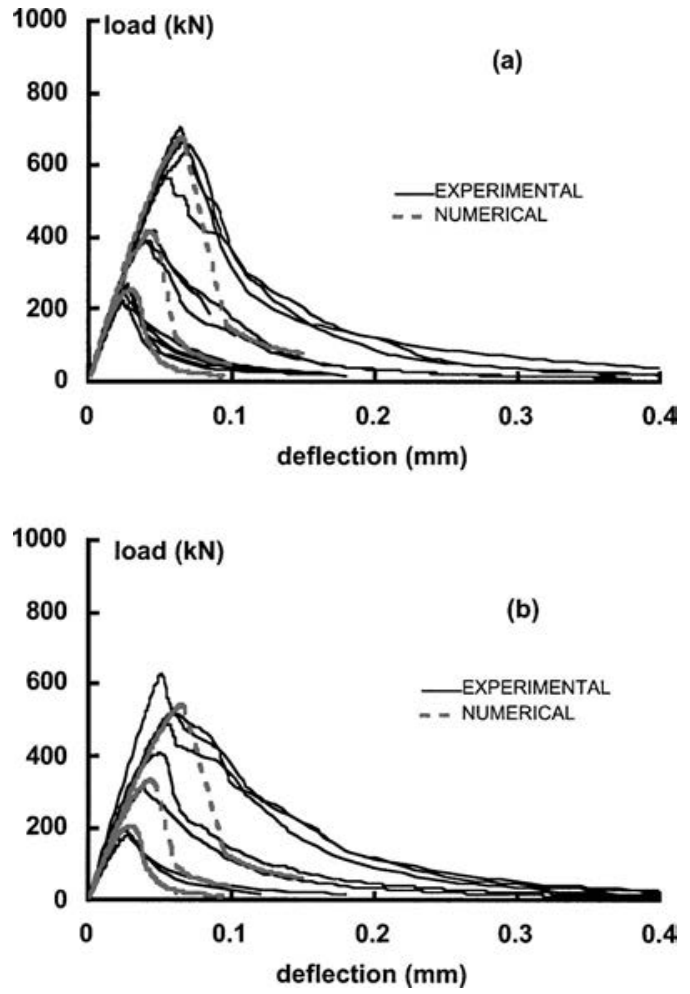

Fig. 6. Prediction of the response of leached beams for two leaching rates (a) $45 \%$ and (b) $64 \%$. Thin lines correspond to experimental lower and upper bounds for each size and thick lines correspond to computations. 
Table 4. Material Characteristics from Size Effect Regression on Experimental Data

\begin{tabular}{lccc}
\hline & $B f_{t}^{\prime}(\mathrm{MPa})$ & $G_{f}(\mathrm{~N} / \mathrm{mm})$ & $D_{0}(\mathrm{~mm})$ \\
\hline Sound & 5.25 & 89 & 416 \\
Leached & 3.04 & 26.9 & 123 \\
\hline
\end{tabular}

$$
\sigma=\frac{3}{2} \frac{F l}{b(0.9 D)^{2}}
$$

where $b=$ thickness of the beam; $D=$ height $(\mathrm{mm}) ; \quad l$ $=\operatorname{span}(\mathrm{mm}) ;$ and $F=$ maximal load $(N)$. The size effect law reads

$$
\sigma=\frac{B f_{t}^{\prime}}{\sqrt{1+D / D_{0}}}
$$

$f_{t}^{\prime}=$ tensile strength of the material; $D_{0}=$ characteristic size which corresponds to a change of failure mechanism between strength of materials and linear elastic fracture mechanics; and $B$ = geometry related parameter. $D / D_{0}$ can be considered as a measure of the structural brittleness. The larger it is, the more brittle the structure which tends to fail according to linear elastic fracture mechanics. $B f_{t}^{\prime}$ and $D_{0}$ are obtained from a linear regression (see Bazant and Plans 1998). The fracture energy $G_{f}$ is also obtained with this regression. Table 4 shows these parameters for sound and entirely leached beams. Note that they are slightly different from the results by Le Bellégo et al. (2000). Additional experiments on the largest beams, not available at the time of publication of this paper and reported in (Le Bellégo 2001; Le Bellégo et al. 2003) have been used. The data interpretation accounts also for the notch in the resisting ligament of the beam whose depth $D$ is decreased accordingly (which was not the case in the original paper).

Fig. 7(a) shows the size effect plots for the computations of sound beams and of leached beams at different leaching rates. Fig. 7(b) shows the experimental results, which are quite different from the computations. These plots have been obtained assuming that the beams are made of a homogeneous material equivalent to the leached and sound material in the cross section. For each stage of leaching, new values of $B f_{t}^{\prime}$ and of $D_{0}$ are obtained from the regression and used to normalize the data in Figs. 7( $a$ and b). The tensile strength $f_{t}^{\prime}$, the parameter $D_{0}$, and the fracture energy which results from these fits of Eq. (14) should not be regarded as intrinsic material properties as they depend on the leaching rate in the cross section of the beam. It is their initial values (sound material) and their asymptotic values (leaching rate of $100 \%$ ) which have a sense in terms of constitutive modeling and therefore are intrinsic, since in these cases the beams are made of a homogeneous material indeed.

Fig. 7(a) shows that the model cannot reproduce the shift of the experimental results to the right on the horizontal axis of the size effect plot, as the leaching rate increases in the beams. This shift, observed on Fig. 7(b), corresponds to an increase of brittleness of the beams upon leaching. For such a shift to be captured, $D_{0}$ should change with the leaching rate at least. One may explain the discrepancy between numerical and experimental results following at least two considerations:

1. Computations performed by Le Bellégo et al. (2003) have shown that $D_{0}$ is proportional to the internal length $l_{c}$ which does not depend on chemical damage here. Hence, $D_{0}$ does not depend on the leaching rate and a shift to the right or left of the data points on the horizontal axis of the size effect plot cannot be described.
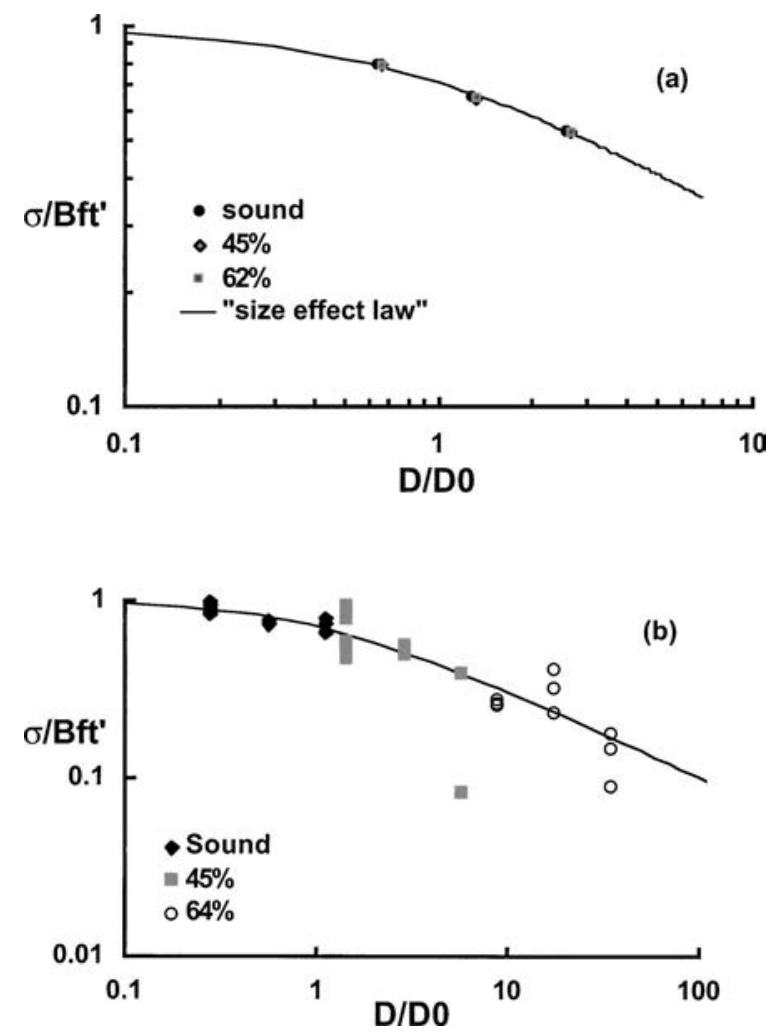

Fig. 7. (a) Prediction of and (b) experimental size effect at several leaching rates

2. $D_{0}$ is a measure of the extend of the fracture process zone, at least it is proportional to Irwin's length

$$
D_{0} \propto \frac{E G_{f}}{\left(f_{t}^{\prime}\right)^{2}}
$$

According to the constitutive relations, the tensile strength of the leached material is $(1-V)$ times the strength of the sound material. The same relationship holds for the Young's modulus and for the fracture energy $G_{f}$ approximately. It follows from Eq. (15) that $D_{0}$ is the same for the sound and leached materials at any stage of chemical damage (here, at any stage of leaching rate since the partially leached beams are assumed to be made of a homogeneous material).

The variation of the mechanical properties that the chemomechanical model should yield from numerical analyses is summarized in Fig. 8. Again, let us emphasize that we have considered for this plot that at any leaching rate, the beams are made of an equivalent homogeneous material for which the size effect formula applies with different normalizing parameters for each leaching rate. It is not the values of the parameters that are important, but their variation as leaching progresses over the beam cross section. Similar trends ought to be reproduced with the numerical model. It is observed on this plot that experimentally $D_{0}$ should decrease but does not in the model. For the completely leached material (leaching rate of $100 \%$ extrapolated from test data following the method by Le Bellégo et al. 2000), the tensile strength decreases by $42 \%$. The fracture energy and the Young's modulus of the beam decrease by 68 and $66 \%$, respectively. Upon inserting these variations in Eq. (15) the decrease of $D_{0}$ (and of the internal length) is $68 \%$ compared to the sound material. It is consistent with the variation of $D_{0}$ obtained experimentally (Fig. 8). From rough estimates and Eq. (15) as well, an increase of the internal length and of the fracture process zone size has been 


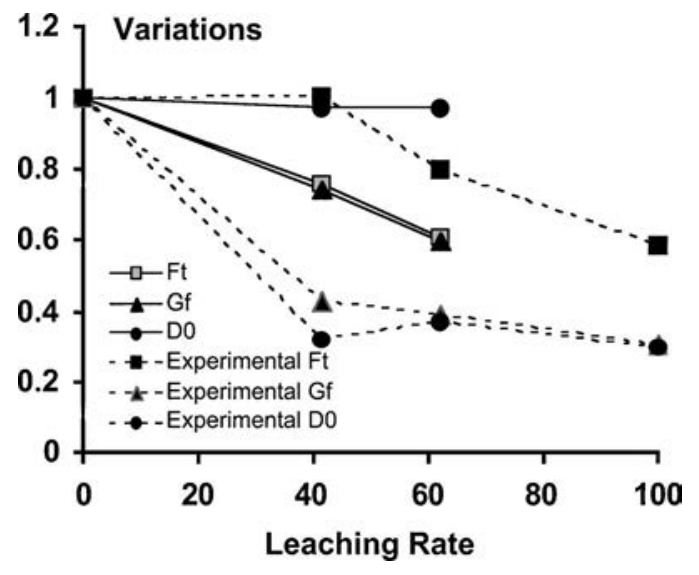

Fig. 8. Experimentally observed variation of tensile strength, fracture energy, and normalizing factor $D_{0}$ as function of leaching rate. Data points corresponding to a leaching rate of $100 \%$ are extrapolation of test data (Le Bellégo et al. 2000).

computed by Heukamp et al. (2001). According to the present experiments, this result would be correct if there is a sudden decrease of the material tensile strength only upon reaching a leaching rate of $100 \%$, which is difficult to expect from the test data.

As indicated by the size effect plots, the present model fails to represent correctly the response of leached specimens of sizes very different from those used for the calibration of the mechanical damage model alone. Developing a new constitutive relation which would encompass the response of the sound and leached materials at the same time is outside the scope of this contribution. It is possible, however, to perform a new calibration of the mechanical damage model assuming that it describes the response of the leached material only. An automatic calibration technique has been used for this purpose. It optimizes the model parameters so as to minimize the errors on the load-deflection curves for the three sizes of three-point bending beams simultaneously. This automatic procedure has been implemented on the sound and on the $100 \%$ degraded beam responses in order to obtain intrinsic constitutive parameters corresponding to the sound and totally leached homogeneous materials. Values lying in between these two stages are hardly accessible because experimentally it is difficult to obtain a homogeneous state of leaching due to the diffusion process at any arbitrary stage of leaching. This prevents any experimental evidence of the variation of the model parameters between the initial and final stages of leaching. The initial parameters in the iterative optimization process are those given in Table 3 for the sound beams and the optimum of the same beams for the leached ones. Note that there is a sensitivity of the optimization to the set of initial data, which results for instance into variations of the internal length in optimal fits of about $10 \%$. For the sound beams, the result obtained by Le Bellégo et al. (2003) is recalled in Table 5. It is slightly different from the set of model parameters

Table 5. Set of Model Parameters for Sound and Leached Materials Resulting from Optimized Fits

\begin{tabular}{lcccccc}
\hline & $\begin{array}{c}l_{c} \\
(\mathrm{~mm})\end{array}$ & $\kappa_{0}$ & $\mathrm{At}$ & $\mathrm{Bt}$ & $(\mathrm{MPa})$ & $v$ \\
\hline Sound & 45.9 & $2.92 \times 10^{-5}$ & 0.72 & 10,000 & 38,500 & 0.24 \\
Leached & 35.3 & $7.41 \times 10^{-5}$ & 0.88 & 10,500 & 13,052 & 0.24 \\
\hline
\end{tabular}

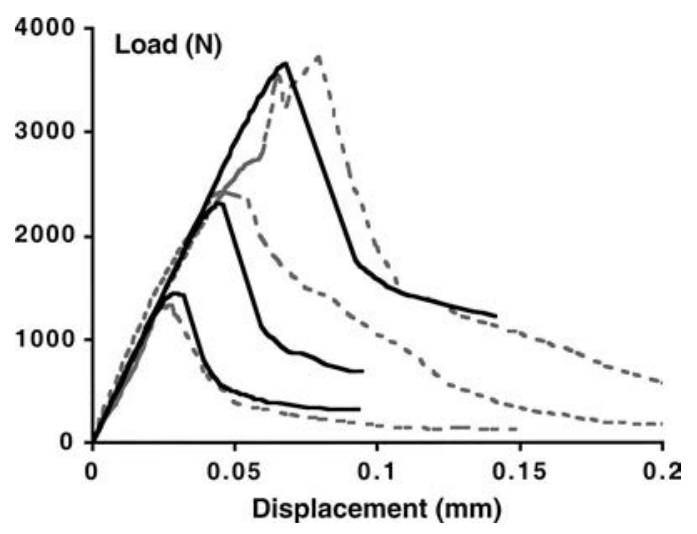

Fig. 9. Size effect experiments—comparison between experimental results (dotted curves) and numerical results (plain curves) obtained after calibration of model for degraded material

given in Table 3 and provides more accurate predictions, in the softening regimes of the beam responses, especially. Table 5 shows also the model parameters obtained for the leached material and Fig. 9 shows the comparison between the experimental data and numerical model. The internal length decreases by $24 \%$ and the damage threshold is multiplied by 2.5 as the material is leached. There is no doubt that such variations are the result of the microstructural changes occurring inside the cement paste upon leaching.

Fig. 10(a) collects on the same normalized size effect plot the experimental and the new numerical results [the normalizing parameters $\left(B f_{t}^{\prime}, D_{0}\right)$ are those of the experiments (Table 4$)$, and different for leached and sound materials]. The extrapolation to completely leached beams is again considered here, same as in Le Bellégo et al. (2000). A good agreement is now reached in both cases. The shift to the right of the size effect data is achieved with an increase of the damage threshold $\kappa_{0}$ and a decrease of the internal length $l_{c}$ simultaneously. The increase of the damage threshold also provides a variation of the tensile strength that is smaller than the decrease of Young's modulus. Fig. 10(b) shows the resulting uniaxial tension curves for the sound and degraded materials. According to the model in the section "Constitutive Relation," the tensile strength of the leached material should be about 0.34 times the strength of the sound material. Due to the increase of damage threshold it is now 0.57 times this strength, same as the ratio obtained from the experiments in Fig. 8.

The computations considered in this paper could be performed with any other constitutive model aimed at describing chemomechanical damage due to calcium leaching. It is found here that the mechanical consequences of leaching are better described if the model parameters in the damage evolution laws are changed.

With the model due to Gérard (1996), the results show that predictions with a good accuracy can be achieved provided that structures of similar sizes and similar geometries are considered. Design of more complex structures, which may not fail due to Mode I fracture only, would require as a first step a mechanical model that is better suited for this purpose [e.g., a damage model coupled to plasticity with damage-induced anisotropy (Fichant et al. 1999)]. Leaching could be incorporated in such a model following the same idea as in the section "chemomechanical coupling," with an independent ageing variable that induces an isotropic change of the stiffness upon chemical degradation.

For structures which fail due to Mode I fracture, of sizes very different from the experiments which served for calibration, a 

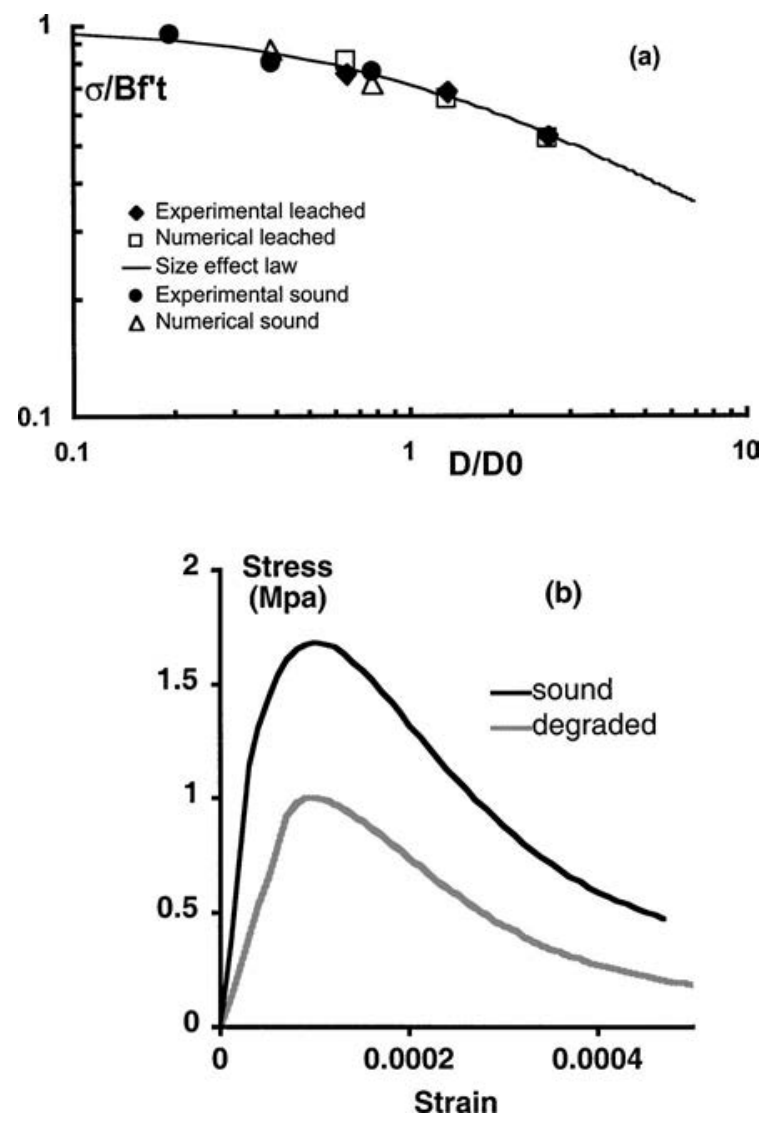

Fig. 10. Comparison between (a) experimental size effect and numerical models and (b) uniaxial tension responses for sound and degraded materials

simplified calculation of their response can be envisioned. The leached zones may be obtained from the solution of the chemical problem (diffusion equation). The leached material could be regarded as a homogeneous material in the mechanical sense (which is an underestimation) and the residual capacity of the structure could be computed assuming that the sound and leached regions of the structure follow the same damage model but with different parameters. Such an approach may provide acceptable results but raises the issues of how to treat nonlocal interactions at the interface between two materials with a different internal length and more generally of boundary conditions in nonlocal models. These are the subjects of ongoing research efforts.

\section{Conclusions}

A constitutive relation aimed at describing the influence of leaching in concrete and mechanical damage has been examined. Sensitivity analyses show that the tensile strength, the fracture energy, and the internal length in the nonlocal mechanical damage model have a strong influence on the lifetime of bending beams subjected to a fixed displacement at midspan and to leaching.

The comparison between the prediction of the response of beams at several leaching rates and the experiments is rather acceptable. Unfortunately, size effect is not well captured. It follows that the extrapolation of the computations to large size structures is delicate because accuracy is lost progressively for larger and larger structures. New model parameters have been obtained for the leached material, in order to achieve a better fit of the re- sponse of totally leached beams. We find that the internal length should decrease and that the damage threshold should increase.

\section{Acknowledgments}

Partial financial support from EDF-R\&D and the ACI "Jeunes Chercheurs" of the French Ministry of Research are gratefully acknowledged.

\section{References}

Bazant, Z., and Planas, J. (1998). Fracture and size effect in concrete and other quasibrittle materials, CRC, Boca Raton, Fla.

Carde, C. (1996). "Characterization and modeling of the alteration of material properties due to leaching of cement-based materials." $\mathrm{PhD}$ thesis, Univ. Paul Sabatier, Toulouse, France, 218 (in French).

Carde, C., and Francois, R. (1997). "Effect of leaching of calcium hydroxyde from cement paste on mechanical and physical properties." Cem. Concr. Res., 27, 539-550.

De Borst, R., Sluys, L. J., Muhlhaus, H. B., and Pamin, J. (1993). "Fundamental issues in finite element analysis of localisation of deformation." Eng. Comput., 10, 99-121.

Díez, P., Arroyo, M., and Huerta, A. (2002). "Adaptive simulation of the coupled chemo-mechanical concrete degradation." Proc., 5th World Congress on Computational Mechanics (WCCM V), July 7-12, Vienna, Austria, H. A. Mang et al., eds., Vienna Univ. of Technology, Austria, 〈http://wccm.tuwien.ac.at〉.

Fichant, S., La Borderie, C., and Pijaudier-Cabot, G. (1999). "Isotropic and anisotropic descriptions of damage in concrete structures." Int. J. Mech. Cohesive Frict. Mater., 4, 339-359.

Gérard, B. (1996). "Contribution of the mechanical, chemical, and transport couplings in the long-term behavior of radioactive waste repository structures." PhD thesis, Dept. de Génie Civil, Univ. Laval, Québec, Canada/École Normale Supérieure de Cachan, France (in French), 278.

Gérard, B., Pijaudier-Cabot, G., and Le Bellégo, C. (1999). Calcium leaching of cement based materials A chemo-mechanics application, construction materials-Theory and application, Hans-Wolf Reinhardt Zum 6 Geburstag, R. Eligehausen, ed., ibidem, 313-329.

Gérard, B., Pijaudier-Cabot, G., and La Borderie, C. (1998). "Coupled diffusion-damage modelling and the implications on failure due to strain localisation." Int. J. Solids Struct., 35, 4105-4120.

Goncalves, A., and Rodrigues, X. (1991). "The resistance of cement to ammonium nitrate attack." Durability of Concrete, 2nd Int. Conf. Montréal.

Heukamp, F. H., Mainguy, M., and Ulm, F. J. (2001). "Beyond the crack size criterion: The effect of fracture on calcium depletion of cementitious materials." Proc., Framcos 4, R. de Borst et al., eds., Balkema, Rotterdam, The Netherlands, 215-221.

Kuhl, D., Bangert, F., and Meschke, G. (2000). "An extension of damage theory to coupled chemo-mechanical processes." Proc., ECCOMAS 2000, Barcelona, Spain.

Le Bellégo, C. (2001). "Couplages chimie-mécanique dans les structures en béton attaquées par l'eau: Etude expérimentale et analyse numérique." PhD dissertation, École Normale Supérieure de Cachan, France, 236.

Le Bellégo, C., Dubé, J. F., Pijaudier-Cabot, G., and Gérard, B. (2003). "Calibration of non local model from size effect tests." Eur. J. Mech. A/Solids, in press.

Le Bellégo, C., Gérard, B., and Pijaudier-Cabot, G. (2000). "Chemomechanical effects in mortar beams subjected to water hydrolysis." $J$. Eng. Mech., 126(3), 266-272.

Mazars, J. (1984). "Application de la mécanique de l'endommagement au comportement non linéaire et à la rupture de béton de structure." 
thèse de Doctorat d'Etat, Univ. Paris VI, France.

Mazars, J., and Pijaudier-Cabot, G. (1996). "From damage to fracture mechanics and conversely: A combined approach." Int. J. Solids Struct., 33, 3327-3342.

Meftah, F., Nechnech, W., and Reynouard, J. M. (2000). "An elastoplastic damage model for plain concrete subjected to combined mechanical and high temperature loads." Proc., EM2000, J. L. Tassoulas, ed., Univ. of Austin, Tex.

Molez, L., Gérard, B., and Pijaudier-Cabot, G. (1998). "Couplage endommagement mécanqiue-Endommagement chimique: Etude d'un modélisation numérique." Rev. Française de Genie Civil, 2, 481-504

Pijaudier-Cabot, G., and Bazant, Z. P. (1987). "Nonlocal damage theory." J. Eng. Mech., 113(10), 1512-1533.

Rodriguez-Ferran, A., and Huerta, A. (2000). "Error estimation and adaptivity for nonlocal models." Int. J. Solids Struct., 37, 7501-7528.

Saetta, A., Scotta, R., and Vitaliani, R. (1999). "Coupled environmentalmechanical damage model of RC structures." J. Eng. Mech., 125(8), 930-940.
Schneider, U., and Chen, S. W. (1998). "The chemomechanical effect and the mechanochemical effect on high-performance concrete subjected to stress corrosion." Cem. Concr. Res., 28, 509-522.

Schneider, U., and Chen, S. W. (1999). "Behavior of high-performance concrete under ammonium nitrate solution and sustained load." $A C I$ Mater. J., 96, 47-51.

Stabler, J., and Baker, G. (2000). "On the form of free energy and specific heat in coupled thermo-elasticity with isotropic damage." Int. J. Solids Struct., 37, 4691-4713.

Ulm, F. J., and Coussy, O. (1996). "Strength growth as chemo-plastic hardening in early age concrete." J. Eng. Mech., 122(12), 1123-1132.

Ulm, F. J, Heukamp, F. H., and Germaine, J. T. (2001). "Durability mechanics of calcium leaching of concrete and beyond." Proc., Fram$\cos 4$, R. de Borst et al., eds., Balkema, Rotterdam, The Netherlands, 133-143.

Ulm, F. J., Torrenti, J. M., and Adenot, F. (1999). "Chemoporoplasticity of calcium leaching in concrete." J. Eng. Mech., 125(10), $1200-1211$. 